\title{
Effects of intra and interspecific interactions on the survival of two predatory ladybirds (Coleoptera: Coccinellidae) in relation to prey abundance
}

\author{
Satoru Sato, ${ }^{1, *}$ Katsuhiro ShInya, ${ }^{1}$ Hironori Yasuda, ${ }^{1}$ Pavel Kindlmann ${ }^{2}$ and \\ Anthony F. G. DIXON ${ }^{3}$ \\ ${ }^{1}$ Department of Agriculture, Yamagata University; Tsuruoka, Yamagata 997-8555, Japan \\ ${ }^{2}$ Faculty of Biological Sciences, University of South Bohemia; Branisovska 31, 37005 Ceske Budejovice, Czech Republic \\ ${ }^{3}$ School of Biological Sciences, University of East Anglia; Norwich NR47TJ, UK
}

(Received 22 September 2008; Accepted 18 November 2008)

\begin{abstract}
The relative effects of intra and interspecific interactions on the larval survival of two species of aphidophagous ladybirds, Coccinella septempunctata brucki and Harmonia axyridis, were assessed at two different prey abundances. In single species rearing, the number of larvae of both species decreased during the latter developmental stages, mainly due to cannibalism. When prey was abundant, the survival of both species improved; however, in mixed species rearing, the mortality of $C$. septempunctata brucki due to cannibalism or intraguild predation was higher than in single species rearing, whereas the mortality was lower in $H$. axyridis. Consequently, the survival of $C$. septempunctata brucki decreased while that of $H$. axyridis improved. In addition, in the 18 intraguild predation events observed, $H$. axyridis was always the intraguild predator and $C$. septempunctata brucki was its prey. Thus, when these two species co-exist in the field, $H$. axyridis is likely to be an important intraguild predator of C. septempunctata brucki. In addition, when prey is scarce, it is likely that cannibalism and intraguild predation become more important factors in the intra and interspecific relationships of these two species.
\end{abstract}

Key words: Cannibalism; guild structure; intraguild predation; intra and interspecific interaction; predatory ladybird

\section{INTRODUCTION}

Competition, predation, and disturbance are important in shaping communities (e.g. Menge and Sutherland, 1987; Begon et al., 1996). Intraguild predation is common among arthropods in agricultural (Rosenheim et al., 1993, 1995; Cisneros and Rosenheim, 1997) and natural ecosystems (Moran and Hurd, 1994; Snyder and Hurd, 1995); therefore, intraguild predation is thought to be an important factor affecting population dynamics and community structure in several taxa of predatory arthropods (Polis et al., 1989; Spence and Carcamo, 1991; Polis and Holt, 1992; Fincke, 1994; Wagner and Wise, 1996; Holt and Polis, 1997; Mizell, 2007; Montserrat et al., 2008).

Many species of predatory arthropods are attracted to sites where aphids are abundant (Sakuratani, 1977; Aalbersberg et al., 1988; Winder et al., 1994; Wyss, 1995; Nakashima and Akashi, 2005; Alhmedi et al., 2007). In these aphidophagous guilds, intraguild predation often occurs and its incidence depends on prey abundance and the developmental stages and species of the predator involved (Takahashi, 1989; Agarwala and Dixon, 1992; Rosenheim et al., 1993; Cisneros and Rosenheim, 1997; Dinter, 1998; Lucas et al., 1998; Obrycki et al., 1998; Phoofolo and Obrycki, 1998).

Of these aphidophagous arthropods, ladybirds are important, and because of their voracity and size they affect the survival of other aphidophagous insects (Lucas et al., 1998; Obrycki et al., 1998); however, the nature and relative strengths of intraguild predation on larval survival have not been quantified. Knowledge of the effect of these interactions on their performance throughout their larval development, when they coexist in the same habitat, is needed for a better understanding of

\footnotetext{
* To whom correspondence should be addressed at: E-mail: Satorus@tds1.tr.yamagata-u.ac.jp
} DOI: $10.1303 /$ aez.2009.215 
their relative importance and role in shaping aphidophagous guilds.

In Japan, Coccinella septempunctata brucki Mulsant and Harmonia axyridis Pallas coexist in the same habitat, e.g., these two species co-occur on Hibiscus syridis Linne, the primary host of the cotton aphid, Aphis gossypii Glover at the farm of Yamagata University in northern Japan (Yasuda and Shinya, 1997). Cannibalism and intraguild predation between these two species are sometimes observed in the field when prey is scarce (Takahashi, 1989; Yasuda and Shinya, 1997), suggesting that intra and interspecific competition may also affect interactions between these two species. The aim of this study was to assess the nature and relative strengths of intra and interspecific interactions between the larvae of ladybirds $C$. septempunctata brucki and $H$. axyridis by determining the relative effects of competition and/or predation on larval survival of these two species when prey is scarce and abundant. The role of these interactions in determining guild structure in ladybirds is discussed.

\section{MATERIALS AND METHODS}

The cotton aphid, A. gossypii, and adults of ladybirds, C. septempunctata brucki and H. axyridis, were collected from hibiscus trees growing in a field at Yamagata University. Adult ladybirds were fed cotton aphids in plastic containers $(15 \mathrm{~cm}$ in diameter and $9 \mathrm{~cm}$ in height) and eggs laid were collected every day. Each egg batch was placed individually in a Petri dish $(9 \mathrm{~cm}$ in diameter) and 24-48 $\mathrm{h}$ after hatching, the larvae were used in experiments. The ladybirds were reared at a constant temperature $\left(25 \pm 1^{\circ} \mathrm{C}\right)$ and photoperiod (16L8D) in a laboratory.

Each hibiscus tree, $60 \mathrm{~cm}$ in height, was planted individually in a standard plant pot, and three aluminum poles $(76 \mathrm{~cm}$ in height) were inserted into the soil around the rim of the pot. Each tree was enclosed in a nylon screen bag, which was taped to the top of the pot. Each tree was infested with approximately 300 (low prey density) or 700 (high prey density) adult cotton aphids and subjected to one of the following treatments, each replicated three times: 10 first instar larvae of C. septempunctata brucki (1) or of $H$. axyridis (2), or five first instar larvae of each of these species (3). Treatments 1 and 2 are referred to as single species experi- ments and treatment 3 as a mixed species experiment. The numbers of aphids and ladybird larvae used in these experiments are within the range of numbers observed in the field (Sato, unpublished data).

The numbers of ladybird larvae and their instar was recorded daily until all ladybirds were dead or had developed into adults. To determine the cause of mortality, the larvae were observed as often as possible and any cannibalism or intraguild predation recorded. In the single species experiments, the disappearance of a larva or presence of parts of a carcass indicated cannibalism, while in the mixed species experiment it indicated either cannibalism or intraguild predation. A shrunken carcass indicated starvation. Death due to a cause other than cannibalism, intraguild predation or starvation was categorized as "other mortality"; that is, the cause of death of a ladybird larva was decided on the basis of the condition of its carcass. All experiments were carried out in a greenhouse. The mean daily temperature in the greenhouse during the experiments was $20-26^{\circ} \mathrm{C}$. Because there were a few replicates and few larvae survived, the results for all replicates of each treatment were pooled. The results were compared using chi-squared tests.

\section{RESULTS}

The number of aphids present was not monitored during the present experiments; however, the developmental stages of larvae of both species when aphids became extinct appeared to depend on initial prey density; there were third and fourth instars, respectively, in the low and high prey density treatments in the following two experiments.

\section{Single species experiment}

In the low prey density treatment, the number of larvae of both species decreased, mainly over the period from the third instar to pupal stage, and none completed their development (Fig. 1-1a); however, in the high prey density treatment, more than $30 \%$ of the larvae of both species completed their development and emerged as adults $(C$. septempunctata brucki: $\chi^{2}=12.0, \quad$ d.f. $=1, \quad p<$ $0.0001 ; H$. axyridis: $\chi^{2}=18.3$, d.f. $=1, p<0.0001$ ) (Fig. 1-1b); that is, although the percentage survival of both species tended to decrease during the latter developmental stages, more survived at the 
(1) Single species

(a) Low prey density

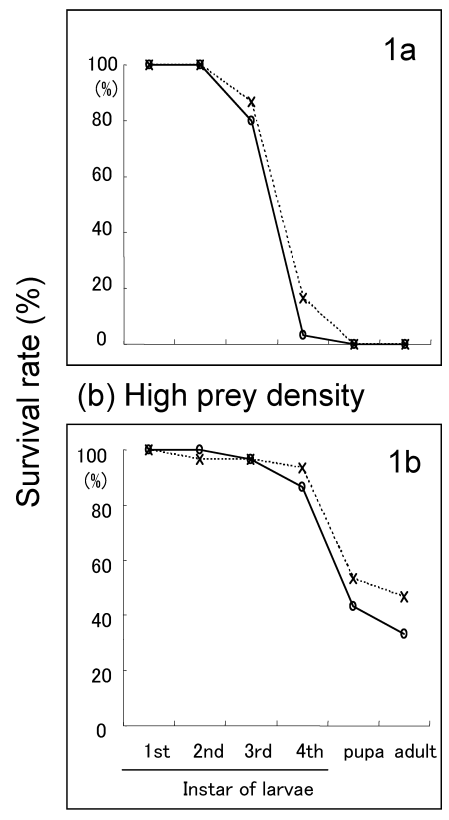

(2) Mixed species
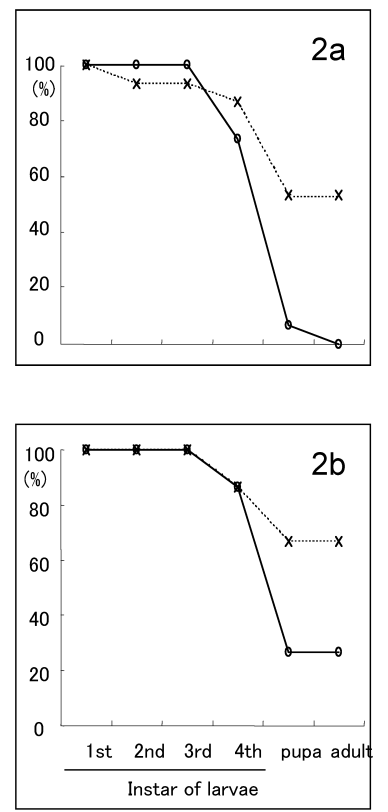

Species

$\rightarrow$ C. septempunctata brucki

.x. H. axyridis

Developmental stages

Fig. 1. Survival rate of two species of aphidophagous ladybirds, C. septempunctata brucki and H. axyridis, at each developmental stage when reared in single and mixed species treatments at two prey population densities.

higher prey density.

In the low prey density treatment, the percentage of larvae of C. septempunctata brucki that died due to cannibalism compared to other causes of mortality differed significantly $\left(\chi^{2}=18.3\right.$, d.f. $=2$, $p<0.0001$ ) (Fig. 2-1a) with cannibalism accounting for 6 times more of the deaths than the other causes of mortality. Similarly, in H. axyridis, cannibalism accounted for most deaths, but the differences in mortality attributable to the different causes of death were not significant $\left(\chi^{2}=3.6\right.$, d.f. $=2, p>0.05)$. Consequently, cannibalism accounted for more deaths in C. septempunctata brucki than $H$. axyridis $\left(\chi^{2}=10.8\right.$, d.f. $=1, p<$ $0.001)$; however, in the high prey density treatment, the percentages of deaths attributable to cannibalism were halved in both species compared with in the low prey density treatment (C. septempunctata brucki: $\chi^{2}=12.4, p<0.0001 ; H$. axyridis: $\chi^{2}=4.8$, $p<0.05$ ) (Fig. 2-1b); that is, in general, the main cause of mortality was cannibalism in both species, and this tended to decrease when prey was abundant.

\section{Mixed species experiment}

Similarly, in the mixed species experiment, at both prey densities, the numbers of larvae of both species tended to decrease during the latter developmental stages (Fig. 1-2a,2b). In the low prey density treatment, no larvae of $C$. septempunctata brucki completed their development (Fig. 1-2a), whereas $53 \%$ of the larvae of $H$. axyridis reached the adult stage, which is significantly more than the $0 \%$ in the single species experiment $\left(\chi^{2}=19.5\right.$, d.f. $=1, p<0.0001$ ) (Fig. 1-1a, 2a). In the high prey density treatment, the percentage of larvae of $H$. axyridis that reached the adult stage was significantly higher than in the single species experiment, but not significantly so $\left(\chi^{2}=0.6\right.$, d.f. $\left.=1, p>0.05\right)$ (Fig. 1-1b, 2b). Twice the number of larvae of $H$. axyridis reached the adult stage than of $C$. septempunctata brucki $\left(\chi^{2}=4.8\right.$, d.f. $=1, p<0.05$, Fig. 1$2 b$ ); that is, at both prey densities, the survival of $H$. axyridis was greatly increased if $C$. septempunctata brucki was present.

In the low prey density treatment, the percentage mortality of larvae of C. septempunctata brucki due to cannibalism or intraguild predation increased slightly to $93 \%$ (Fig. 2-2a), which is simi- 
(1) Single species

(a) Low prey density

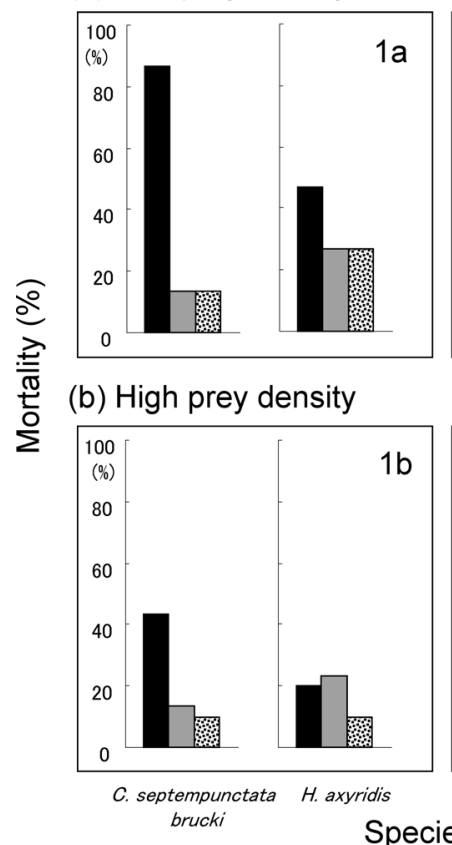

(2) Mixed species

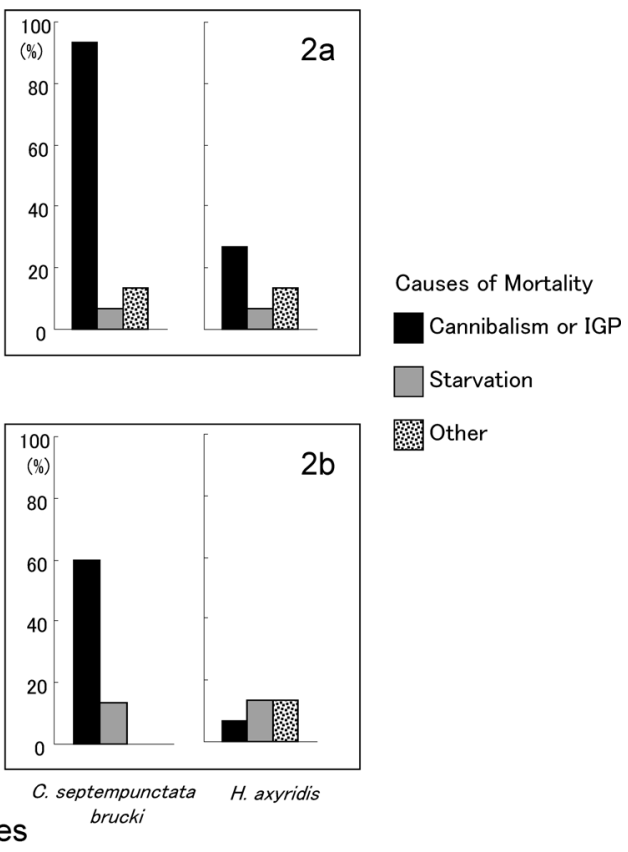

Fig. 2. Mortality rate of the larvae of two species of aphidophagous ladybirds, C. septempunctata brucki and H. axyridis, attributable to cannibalism or intraguild predation (IGP), starvation or other when reared in single or mixed species treatments at either a low or high prey population density.

lar to that in the single species experiment $\left(\chi^{2}=0.5\right.$, d.f. $\left.=1, p>0.05\right)$ (Fig. 2-1a). In contrast, the percentage mortality of larvae of $H$. axyridis due to cannibalism or intraguild predation decreased by $20 \%$ (Fig. 2-2a), but the difference from that in the single species experiment was not significant $\left(\chi^{2}=1.7\right.$, d.f. $=1, p>0.05$, Fig. 2-1a). Also, in the high prey density treatment, the percentage mortality due to cannibalism or intraguild predation in C. septempunctata brucki increased (Fig. 22b), whereas in $H$. axyridis it decreased; however, the differences between single and mixed species experiments were not significant (C. septempunctata brucki: $\chi^{2}=1.1$, d.f. $=1, p>0.05 ; H$. axyridis: $\chi^{2}=1.4$, d.f. $=1, p>0.05$ ); that is, the presence of other species differently affects the incidence of cannibalism or intraguild predation in these two species. In addition, 28 individuals died due to cannibalism or intraguild predation in mixed species experiments. Of these, 18 cases were observed, and $H$. axyridis was the intraguild predator and $C$. septempunctata brucki was the prey in all cases.

\section{DISCUSSION}

Our results indicate that cannibalism and intraguild predation were important mortality factors in intra- and interspecific relationships between two species of ladybird when aphids were scarce. $H$. axyridis was the intraguild predator and $C$. septempunctata brucki was its prey throughout larval development, particularly so during the latter developmental stages.

Body size, mobility, feeding specificity and prey abundance significantly affect the vulnerability of organisms to intraguild predation (Agarwala and Dixon, 1992; Lucas et al., 1998). The present study also indicates that prey abundance determines the incidence of intraguild predation and/or cannibalism. Coccinella septempunctata brucki and $H$. axyridis are similar in size (Yasuda and Kimura, 2001); however, in terms of feeding specificity $H$. axyridis is polyphagous and C. septempunctata brucki is more aphid-specific (Hodek and Honek, 1988; Lucas et al., 1997; Yasuda and Ohnuma, 1999; Sato et al., 2008). Harmonia axyridis is more aggressive and more successful in its attacks on conspecific or heterospecific individuals than $C$. 
septempunctata brucki (Yasuda et al., 2001). In addition, in the present study, in all cases of intraguild predation observed, $H$. axyridis consumed C. septempunctata brucki. These results indicate that, in this system, H. axyridis is the intraguild predator and C. septempunctata brucki is its prey. The relationship between these two species is likely to be a consequence of differences in feeding specificity and predatory behavior.

Evans (1991) indicated that the magnitude of the effect of intra- and interspecific competition between species is similar, whereas Obrycki et al. (1998) shows that it depends on species. These interactions might differ due to the species involved. One of the objectives of our experiments was to determine the effect of competitive interactions between larvae of $C$. septempunctata brucki and $H$. axyridis on larval developmental time and adult size; however, it is likely that before interspecific competition occurred, $H$. axyridis larvae ate the $C$. septempunctata brucki larvae and, as a consequence, interspecific competition for food did not occur; therefore, in the interaction between these two species, intraguild predation might be more important than interspecific competition.

A field study of the population dynamics of $C$. septempunctata brucki and $H$. axyridis in Japan indicated that mortality during the fourth instar is a key stage in both species (Kindlmann et al., 2000). In the present experiments, the mortality of both species increased during the latter developmental stages; however, the experiments reported here were performed in enclosures, which prevented the predators from dispersing. Therefore, the results may not indicate the precise nature of the mechanism by which $H$. axyridis dominates this ladybird assemblage. In fact, a previous study showed that larvae of $C$. septempunctata brucki are more likely to emigrate from trees when aphids become scarce than $H$. axyridis (Sato et al., 2003), which suggests that dispersal by late stage larvae of $C$. septempunctata brucki could be an important factor determining their survival.

Cannibalism is common in predatory arthropods (e.g., Elgar and Crespi, 1992) and is frequently recorded in ladybirds (Mills, 1982; Osawa, 1989; Hodek and Honek, 1996); for example, in the wolf spider, Schizocosa ocreata (Hentz), cannibalism acts as a strong density-dependent mortality factor regulating the population density of this spider
(Wagner and Wise, 1996) and similarly is also thought to contribute to the population regulation of dragonfly larvae (Van Buskirk, 1989; Hopper et al., 1996). In the present study, cannibalism was recorded in both species and was dependent on both prey abundance and developmental stage. As fourth instar larvae of C. septempunctata brucki and $H$. axyridis can often survive and develop to the adult stage by eating only conspecific larvae (Yasuda and Ohnuma, 1999), cannibalism is clearly advantageous when aphids become scarce. Previous analyses indicated that the key factor in the population dynamics of $C$. septempunctata brucki and $H$. axyridis is larval survival, particularly in the fourth instar (Osawa, 1993; Kindlmann et al., 2000). Thus, intraguild predation acting on $C$. septempunctata brucki and cannibalism in $H$. axyridis might be important factors determining the population dynamics of these two species.

Intraguild predation often occurs in aphidophagous guilds (Rosenheim et al., 1993, 1995; Cisneros and Rosenheim, 1997; Dinter, 1998; Lucas et al., 1998; Obrycki et al., 1998). In ladybird guilds, $H$. axyridis is thought to be a top predator (Dixon, 2000); therefore, in order to understand how $H$. axyridis affects the survival of other species in aphidophagous guilds it is important to have a better understanding of the ecology of all ladybirds in a guild.

\section{REFERENCES}

Aalbersberg, Y. K., M. C. Van der Westhuizen and P. H. Hewiit (1988) Natural enemies and their impact on Diuraphis noxia (Mordvilko) (Hemiptera: Aphididae) populations. Bull. Entomol. Res. 78: 111-120.

Agarwala, B. K. and A. F. G. Dixon (1992) Laboratory study of cannibalism and interspecific predation in ladybirds. Ecol. Entomol. 17: 303-309.

Alhmedi, A., E. Haubruge, B. Bodson and F. Francis (2007) Aphidophagous guilds on nettle (Urtica dioica) strips close to fields of green pea, rape and wheat. Insect Sci. 14: 419-424.

Begon, M., J. L. Harper and C. R. Townsend (1996) Ecology. Blackwell Science, Oxford. 1,068 pp.

Cisneros, J. J. and J. A. Rosenheim (1997) Ontogenetic change of prey preference in the generalist predator Zelus renardii and its influence on predator-predator interactions. Ecol. Entomol. 22: 399-407.

Dinter, A. (1998) Intraguild predation between erigonid spiders, lacewing larvae and carabids. J. Appl. Entomol. 122: $163-167$.

Dixon, A. F. G. (2000) Insect Predator-Prey Dynamics: Ladybird Beetles and Biological Control. Cambridge Uni- 
versity Press, London. 268 pp.

Elgar, M. A. and B. J. Crespi (1992) Cannibalism: Ecology and Evolution of Cannibalism among Diverse Taxa. Oxford University Press, New York. 361 pp.

Evans, E. W. (1991) Intra versus interspecific interactions of ladybeetles (Coleoptera: Coccinellidae) attacking aphids. Oecologia 87: 401-408.

Fincke, O. M. (1994) Population regulation of a tropical damselfly in the larval stage by food limitation, cannibalism, intraguild predation and habitat drying. Oecologia 100: 118-127.

Hodek, I. and A. Honek (1988) Sampling, rearing and handling of aphid predators. In Aphids, Their Biology, Natural Enemies and Control. Vol. 2B (A. K. Minks and P. Harrewijn, eds.). Elsevier, Amsterdam, pp. 311-321.

Hodek, I. and A. Honek (1996) Ecology of Coccinellidae. Kluwer Academic Publishers, Dordrecht. 464 pp.

Holt, R. D. and G. A. Polis (1997) A theoretical framework for intraguild predation. Am. Nat. 149: 745-764.

Hopper, K. R., P. H. Crowley and D. Kielman (1996) Density dependence, hatching synchrony, and within-cohort cannibalism in young dragonfly larvae. Ecology 77: 191200.

Kindlmann, P., H. Yasuda, S. Sato and K. Shinya (2000) Key life stages of two predatory ladybird species. Eur. J. Entomol. 97: 495-499.

Lucas, E., D. Coderre and C. Vincent (1997) Voracity and feeding preferences of two aphidophagous coccinellids on Aphis citricola and Tetranychus urticae. Entomol. Exp. Appl. 85: 151-159.

Lucas, E., D. Coderre and J. Brodeur (1998) Intraguild predation among aphid predators: characterization and influence of extraguild prey density. Ecology 79: 10841092.

Menge, B. A. and J. P. Sutherland (1987) Community regulation: variation in disturbance, competition, and predation in relation to environmental stress and recruitment. Am. Nat. 130: 730-757.

Mills, N. J. (1982) Voracity, cannibalism and coccinellid predation. Ann. Appl. Biol. 101: 144-148.

Mizell, R. F. (2007) Impact of Harmonia axyridis (Coleoptera: Coccinellidae) on native arthropod predators in pecan and crape myrtle. Florida Entomol. 90: $524-536$

Montserrat, M., S. Magalhaes, M. W. Sabelis, A. M. de Roos and A. Janssen (2008) Patterns of exclusion in an intraguild predator-prey system depend on initial conditions. J. Anim. Ecol. 77: 624-630.

Moran, D. M. and L. E. Hurd (1994) Short-term responses to elevated predator densities: noncompetitive intraguild interactions and behavior. Oecologia 98: 269-273.

Nakashima, Y. and M. Akashi (2005) Temporal and withinplant distribution of the parasitoid and predator complexes associated with Acyrthosiphon pisum and A. kondoi (Homoptera: Aphididae) on alfalfa in Japan. Appl. Entomol. Zool. 40: 137-144.

Obrycki, J., K. L. Giles and A. M. Ormord (1998) Interactions between an introduced and indigenous coccinellid species at different prey densities. Oecologia 117:
$279-285$

Osawa, N. (1989) Sibling and non-sibling cannibalism by larvae of a ladybird beetle Harmonia axyridis Pallas (Coleoptera: Coccinellidae) in the field. Res. Popul. Ecol. 31: 153-160.

Osawa, N. (1993) Population field studies of the aphidophagous ladybird beetle Harmonia axyridis (Coleoptera: Coccinellidae): life tables and key factor analysis. Res. Popul. Ecol. 35: 335-348.

Phoofolo, M. W. and J. J. Obrycki (1998) Potential for intraguild predation and competition among predatory Coccinellidae and Chrysopidae. Entomol. Exp. Appl. 89: $47-55$.

Polis, G. A. and R. Holt (1992) Intraguild predation: the dynamics of complex trophic interactions. Trends Ecol. Evol. 7: 151-154.

Polis, G. A., C. A. Myers and R. Holt (1989) The evolution and ecology of intraguild predation: competitors that eat each other. Annu. Rev. Ecol. Syst. 20: 297-330.

Rosenheim, J. A., R. Lawrence, R. Wilhoit and C. A. Armer (1993) Influence of intraguild predation among generalist insect predators on the suppression of an herbivore population. Oecologia 96: 439-449.

Rosenheim, J. A., H. K. Kaya, L. E. Ehler, J. J. Marois and B. A. Jaffee (1995) Intraguild predation among biologicalcontrol agents: theory and evidence. Biol. Control 5: 303-335.

Sakuratani, Y. (1977) Population fluctuations and spatial distributions of natural enemies of aphids in corn fields. Jap. J. Ecol. 27: 291-300.

Sato, S., A. F. G. Dixon and H. Yasuda (2003) Effect of emigration on cannibalism and intraguild predation in aphidophagous ladybirds. Ecol. Entomol. 28: 628-633.

Sato, S., R. Jimbo, H. Yasuda and A. F. G. Dixon (2008) Cost of being an intraguild predator in predatory ladybirds. Appl. Entomol. Zool. 43: 143-147.

Snyder, W. E. and L. E. Hurd (1995) Egg-hatch phenology and intraguild predation between two mantid species. Oecologia 104: 496-500.

Spence, J. R. and H. A. Carcamo (1991) Effects of cannibalism and intraguild predation on pondskaters (Gerridae). Oikos 62: 333-341.

Takahashi, K. (1989) Intra- and interspecific predations of lady beetles in spring alfalfa fields. Jap. J. Entomol. 57: 199-203.

Van Buskirk, J. (1989) Density-dependent cannibalism in larval dragonflies. Ecology 70: 1442-1449.

Wagner, D. J. and D. W. Wise (1996) Cannibalism regulates densities of young wolf spiders: evidence from field and laboratory experiments. Ecology 77: 639-652.

Winder, L., D. J. Hirst, N. Carter, S. D. Wratten and P. I. Sopp (1994) Estimating predation of the grain aphid Sitobion avenae by polyphagous predators. J. Appl. Ecol. 31: $1-12$.

Wyss, E. (1995) The effects of weed strips on aphids and aphidophagous predators in an apple orchard. Entomol. Exp. Appl. 75: 43-49.

Yasuda, H. and T. Kimura (2001) Interspecific interactions in a tri-trophic arthropod system: effects of a spider on the 
survival of larvae of three predatory ladybirds. Entomol. Exp. Appl. 98: 17-25.

Yasuda, H. and N. Ohnuma (1999) Effect of cannibalism and predation on the larval performance of two ladybird beetles. Entomol. Exp. Appl. 93: 63-67.

Yasuda, H. and K. Shinya (1997) Cannibalism and interspe- cific predation in two predatory ladybirds in relation to prey abundance in the field. Entomophaga 42: 153-163. Yasuda, H., T. Kikuchi, P. Kindlmann and S. Sato (2001) Relationship between attack and escape rates, cannibalism and intraguild predation in the larvae of two predatory ladybirds. J. Ins. Behav. 14: 373-384. 